\title{
The impact of a genomic assay (Oncotype DX) on adjuvant treatment recommendations in early breast cancer
}

\section{Richard H de Boer MB BS, FRACP Medical Oncologist ${ }^{1,2}$ \\ Caroline Baker MB BS, FRACS Director \\ David Speakman MB BS, FRACS Surgeon ${ }^{4}$ \\ Calvin Y Chao Senior Director, Medica Affairs $^{5}$ \\ Carl Yoshizawa Vice President Clinical Biostatistics \\ G Bruce Mann MB BS, PhD, FRACS Director, ${ }^{2}$ and Professor ${ }^{6}$ \\ 1 Royal Melbourne Hospital Melbourne, VIC \\ 2 Breast Service, Royal Melbourne Hospital and Royal Women's Hospital Melbourne, VIC \\ 3 Breast Service Austin Health, Melbourne, VIC \\ 4 Peter MacCallum Cancer Centre, Melbourne, VIC \\ 5 Genomic Health Redwood City, Calif, USA. \\ 6 Department of Surgery, University of Melbourne Melbourne, VIC.}

bruce.mann@mh.org.au

MJA 2013; 199: 205-208 doi: 10.5694/mjal2.11334

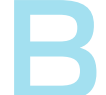

reast cancer is the most common malignancy in Australian women and most of these tumours are hormone receptor-positive $(\mathrm{HR}+){ }^{1-3}$ Adjuvant therapy for invasive breast cancer has been shown to improve survival. ${ }^{4}$ For early-stage, HR+, human epidermal growth factor receptor 2-negative (HER2-) cancer, this therapy may consist of hormonal therapy (HT), or a combination of chemotherapy and hormonal therapy (CHT). It is accepted that the vast majority of patients with $\mathrm{HR}+$, HER2- tumours should receive HT; however, the threshold for use of CHT is difficult to define because this group includes patients with a spectrum of recurrence risks. ${ }^{4,5} \mathrm{~A}$ large number of patients in whom the disease would not recur still receive CHT because accurate tools to help define the benefit of adjuvant chemotherapy have not been available. ${ }^{6,7}$

The 21-gene Oncotype DX breast cancer assay (Genomic Health) was developed on mRNA extracted from archived tumour samples of 447 patients from three studies. The expression patterns of 21 genes were used to develop an algorithm that yields a recurrence score. The score has been validated to quantify the risk of distant recurrence in patients treated with tamoxifen and who had both $\mathrm{HR}+$, lymph node-negative or lymph node-positive disease, as well as to predict the magnitude of benefit from the addition of chemotherapy to tamoxifen treatment. ${ }^{8-11}$ The assay has been widely available in the United States since 2004, and is available in Australia for $\$ 4000$. There have been a number of studies examining the effect of the Oncotype DX assay on clinical decision making. ${ }^{12-17}$ The results have been fairly consistent, showing a shift in the treatment decision in about $30 \%$ of patients. ${ }^{12-15,17}$

These studies have largely focused on decisions made by individual practitioners. In Australia, the multidisciplinary meeting (MDM) has become

\begin{abstract}
Objectives: To assess how the recurrence score of the Oncotype DX breast cancer assay influences adjuvant systemic treatment decisions in the multidisciplinary meeting (MDM) for patients with early breast cancer (EBC) in Australia.

Design, setting and participants: A before-and-after study at three academic medical centres in Melbourne with patients and physicians serving as their own controls. Paired systemic adjuvant treatment recommendations were made in multidisciplinary meetings (MDMs) before and after Oncotype DX testing. Medical oncologists and surgeons, treating patients with unifocal, hormone receptor-positive, human epidermal growth factor receptor 2-negative, node-negative or node-positive early breast cancer.
\end{abstract}

Main outcome measures: Changes in physician treatment recommendations.

Results: This study enrolled 151 eligible patients between 1 November 2010 and 30 September 2011. Of these, 101 patients (67\%) had node-negative and $50(33 \%)$ had node-positive tumours. Recurrence score information resulted in treatment recommendation changes for 24 patients with node-negative tumours (24\%) and for 13 patients with node-positive tumours (26\%). The proportional change from chemo-hormonal therapy $(\mathrm{CHT})$ to hormonal therapy (HT) was significantly greater than from $\mathrm{HT}$ to $\mathrm{CHT}$ for patients with nodenegative tumours (23\% difference in proportions; $P=0.02$ ), and of similar magnitude for patients with node-positive tumours (25\% difference in proportions; $P=0.14$ ).

Conclusion: The Oncotype DX recurrence score has a major impact on adjuvant treatment decision making in the MDM setting.

the standard forum for determining treatment recommendations. A national goal is for all patients to have their treatment decisions discussed in an MDM before definitive treatment recommendations are made. ${ }^{18}$ In this study, we have assessed the effect of recurrence score information on treatment recommendations in the MDM.

\section{Methods}

\section{Study design}

The study was conducted between November 2010 and September 2011 at three institutions in Melbourne, Australia: the Royal Melbourne Hospital, the Peter MacCallum Cancer Centre and Austin Health. Approval was obtained from the human research ethics committees of $\mathrm{Mel}$ bourne Health, the Peter MacCallum Cancer Centre and Austin Health. All medical oncologists and surgeons who participated in the MDMs were eligible to participate. Eligible patients included women with $\mathrm{HR}+$ and HER2- early breast cancer and 0-3 positive nodes. Sequential eligible patients were offered enrollment.

After surgery and a pathology evaluation performed in the pathology department of the respective institutions, each patient was reviewed in the MDM and a treatment recommendation was made. Oestrogen receptor (ER), progesterone receptor (PR) and HER2 status was routinely assessed in all participating institutions, but testing for antigen Ki-67 levels was not a routine part of preassay assessments. The MDMs were typically attended by surgeons, medical oncologists, radiation oncologists, breast care nurses, radiologists and pathologists. Attendance varied little throughout the course of the study. Consenting patients discussed their treatment recommendation with the treating physician at the first postoperative visit. The Oncotype DX assay 
1 Patient and tumour characteristics of 151 women with early breast cancer

\begin{tabular}{lccc} 
& & No. of positive nodes (\% of patients)* \\
\cline { 3 - 4 } Characteristics & Patients (\%) & 0 & $1-3$ \\
\hline All & $151(100 \%)$ & $101 / 151\left(67 \%{ }^{\dagger}\right)$ & $50 / 151\left(33 \%{ }^{\dagger}\right)$ \\
Mean age (years) & 56.2 & 56.6 & 55.3 \\
Tumour size & & & \\
$<2 \mathrm{~cm}$ & $103(68 \%)$ & $71(70 \%)$ & $32(64 \%)$ \\
$\geqslant 2 \mathrm{~cm}$ & $48(32 \%)$ & $30(30 \%)$ & $18(36 \%)$ \\
Tumour grade & & & \\
1 & $29(19 \%)$ & $22(22 \%)$ & $7(14 \%)$ \\
2 & $84(56 \%)$ & $51(50 \%)$ & $33(66 \%)$ \\
3 & $38(25 \%)$ & $28(28 \%)$ & $10(20 \%)$ \\
Hormone receptor status & & & $46(92 \%)$ \\
ER-positive, PR-positive & $136(90 \%)$ & $90(89 \%)$ & $3(6 \%)$ \\
ER-positive, PR-negative & $14(9 \%)$ & $11(11 \%)$ & $1(2 \%)$ \\
ER-negative, PR-positive & $1(1 \%)$ & 0 & $25(50 \%)$ \\
Recurrence score & & & $19(38 \%)$ \\
Low $(<18)$ & $72(48 \%)$ & $47(47 \%)$ & $6(12 \%)$ \\
Intermediate (18-30) & $59(39 \%)$ & $40(40 \%)$ & $14(14 \%)$ \\
High $(\geqslant 31)$ & $20(13 \%)$ &
\end{tabular}

ER = oestrogen receptor. $\mathrm{PR}=$ progesterone receptor. $*$ Percentage of patients in each column except where otherwise indicated. $\dagger$ Percentage of total patients.

was ordered and a tumour sample was sent to the Genomic Health laboratory for analysis. After the assay result was received, the case was discussed in the MDM and a second treatment recommendation was made. The final treatment recommendation was then discussed with the patient.

The primary aim of the study was to characterise the impact of the Oncotype DX assay on the MDM treatment recommendation, as measured by a change in the recommendation. This was assessed separately in the nodenegative and the node-positive group. Other objectives included determin- ing the actual treatment decision of the patient.

\section{Statistical analyses}

The study was designed to enrol at least 80 patients with node-negative tumours and at least 50 with nodepositive tumours. The proportions of treatment recommendations that changed from before to after the assay were calculated. The Fisher exact test was used to compare the difference in the proportions of patients whose recommendation moved from CHT to HT versus those who moved from HT to CHT. The

\begin{tabular}{|c|c|c|c|c|c|c|c|}
\hline \multirow[b]{2}{*}{$\begin{array}{l}\text { Nodal } \\
\text { status }\end{array}$} & \multicolumn{2}{|c|}{ Before Oncotype DX testing } & \multicolumn{2}{|c|}{ After Oncotype DX testing } & \multicolumn{3}{|c|}{$\begin{array}{l}\text { Change from pre-Oncotype DX } \\
\text { recommendation* }\end{array}$} \\
\hline & $\begin{array}{l}\text { Therapy } \\
\text { recommendation }\end{array}$ & Patients & $\begin{array}{l}\text { Patients } \\
\text { recommended } \\
\text { HT }\end{array}$ & $\begin{array}{c}\text { Patients } \\
\text { recommended } \\
\text { CHT }\end{array}$ & $\begin{array}{l}\text { Proportion (\%) } \\
\text { changed }\end{array}$ & $\begin{array}{l}\text { Difference } \\
\text { between } \\
\text { proportions } \\
\text { changed }\end{array}$ & $P^{\dagger}$ \\
\hline \multirow{3}{*}{$\begin{array}{l}\text { Node- } \\
\text { negative }\end{array}$} & $\mathrm{HT}$ & 71 & 59 & 12 & $12 / 71(17 \%)$ & $23 \%$ & 0.020 \\
\hline & $\mathrm{CHT}$ & 30 & 12 & 18 & $12 / 30(40 \%)$ & & \\
\hline & Total & 101 & 71 & 30 & $24 / 101(24 \%)$ & & \\
\hline \multirow{3}{*}{$\begin{array}{l}\text { Node- } \\
\text { positive }\end{array}$} & $\mathrm{HT}$ & 13 & 12 & 1 & $1 / 13(8 \%)$ & $25 \%$ & 0.141 \\
\hline & $\mathrm{CHT}$ & 37 & 12 & 25 & $12 / 37(32 \%)$ & & \\
\hline & Total & 50 & 24 & 26 & $13 / 50(26 \%)$ & & \\
\hline
\end{tabular}

$\mathrm{CHT}=$ combination of chemotherapy and hormonal therapy. $\mathrm{HT}=$ hormonal therapy. $*$ The proportion of patients with nodenegative tumours who were recommended CHT was unchanged from before (30\%) to after Oncotype DX testing (30\%) $(P=1.00$, McNemar test). The proportion of patients with node-positive tumours who were recommended CHT decreased from before $(74 \%)$ to after testing $(52 \%)(P=0.003$, McNemar test). $+P$ from Fisher exact test for the difference in change rates between patients originally recommended $\mathrm{CHT}$ versus those originally recommended $\mathrm{HT}$.
McNemar test was used to assess the change in the proportion of patients who received a recommendation for CHT after the Oncotype DX assay. Exact $P$ values are presented. The statistical software used was SAS version 9.2 (SAS Institute).

\section{Results}

\section{Patient and tumour characteristics}

One hundred and sixty-one patients were enrolled between 1 November 2010 and 30 September 2011. Of these, 10 were determined to be ineligible: three had HER2-positive tumours, two had multifocal cancer, one had HR-negative disease, and four patients' samples were unsuitable for Oncotype DX testing. Therefore, 151 patients were eligible: 101 (67\%) had node-negative tumours and $50(33 \%)$ had node-positive tumours. Patient and tumour details including recurrence scores are shown in Box 1.

\section{Recurrence score impact on MDM recommendations}

For the 101 patients in the nodenegative group, the initial recommendations were for HT alone in 71 patients and for CHT in 30 patients (Box 2). Following receipt of the recurrence score information, there was an overall change rate of $24 \%$ (24/ 101), consisting of changes from CHT to HT in 12 patients and from HT to CHT in another 12 patients. Therefore, the overall proportion of patients with node-negative tumours who received a final recommendation for $\mathrm{CHT}$ was unchanged from pre-assay to post-assay $(P=1, \mathrm{McNemar}$ test). However, within the pre-assay recommendation groups, 12 of the 30 CHT patients (40\%) had their recommendation changed to HT, while only 12 of the 71 HT patients (17\%) had their recommendations changed to $\mathrm{CHT}$. The difference in these rates of change $(23 \%)$ is statistically significant $(P=0.02$, Fisher exact test).

A greater proportion of the 50 patients with node-positive tumours received a pre-assay recommendation for CHT (37 patients) versus HT (13 patients) (Box 2). Thirteen patients in the node-positive group (26\%) had their treatment recommendation 
changed after receiving a recurrence score: from CHT to HT in 12 patients (24\%) and from HT to CHT in one patient $(2 \%)$. There was a significant decrease in the proportion of patients with node-positive tumours who received a recommendation for $\mathrm{CHT}$ from before the assay $(37 / 50 ; 74 \%)$ to after the assay $(26 / 50 ; 52 \%)(P=0.003$, McNemar test).

Details of patients with a changed recommendation are shown in Box 3 and Box 4. The change in treatment recommendation after the assay was consistent with the recurrence score category, and most of those whose recommendations were changed were in the low or high recurrence score category or close to the cut-off between categories.

Of the 12 patients with node-negative tumours whose recommendations changed from CHT to HT, eight had a low recurrence score and four an intermediate result. No patients with a high recurrence score were switched from CHT to HT. Of the 12 patients with node-negative tumours and whose recommendations were changed from HT to CHT, six had an intermediate recurrence score and six had a high score.

Similar results were seen in the node-positive group. The patient whose recommendation changed from HT to CHT had a high recurrence score (37). Of the 12 patients with node-positive tumours whose recommendations were changed from CHT to HT, nine had a low score and three had an intermediate score.

\section{Patient decisions}

Fifteen patients chose not to follow the recommendation of the MDM. In the node-negative group, 10/101 patients decided against the postassay treatment recommendation: four opted for CHT instead of HT, four selected HT instead of CHT, and two refused all therapy. In the nodepositive group, 5/50 opted for a different therapy than the post-assay recommendation: two selected CHT instead of HT, and three selected HT instead of CHT.

\section{Discussion}

This first decision-impact study of the Oncotype DX breast cancer assay in

\begin{tabular}{|c|c|c|c|c|c|c|c|c|}
\hline \multicolumn{4}{|c|}{ Node-negative } & \multicolumn{5}{|c|}{ Node-positive } \\
\hline $\begin{array}{l}\text { Patient } \\
\text { age }\end{array}$ & $\begin{array}{c}\text { Tumour } \\
\text { size }(\mathrm{mm})\end{array}$ & $\begin{array}{l}\text { Tumour } \\
\text { grade }\end{array}$ & $\begin{array}{l}\text { Recurrence } \\
\text { score }\end{array}$ & Patient age & $\begin{array}{c}\text { Tumour } \\
\text { size }(\mathrm{mm})\end{array}$ & $\begin{array}{l}\text { Tumour } \\
\text { grade }\end{array}$ & $\begin{array}{l}\text { Recurrence } \\
\text { score }\end{array}$ & $\begin{array}{c}\text { No. of } \\
\text { positive nodes }\end{array}$ \\
\hline 37 & 47 & 2 & 2 & 56 & 25 & 2 & 10 & 1* \\
\hline 62 & 20 & 3 & 3 & 50 & 20 & 2 & 12 & 1 \\
\hline 51 & 45 & 2 & 6 & 50 & 24 & 2 & 12 & $1^{*}$ \\
\hline 56 & 25 & 2 & 11 & 49 & 21 & 2 & 13 & $1^{*}$ \\
\hline 54 & 25 & 2 & 11 & 75 & 18 & 2 & 14 & 2 \\
\hline 77 & 53 & 2 & 12 & 45 & 57 & 2 & 14 & $1 *$ \\
\hline 40 & 15 & 3 & 17 & 47 & 24 & 2 & 14 & $1 *$ \\
\hline 38 & 33 & 2 & 17 & 58 & 20 & 2 & 16 & 1 \\
\hline 76 & 20 & 3 & 18 & 52 & 18 & 3 & 17 & $1 *$ \\
\hline 62 & 15 & 2 & 20 & 63 & 15 & 2 & 19 & 1 \\
\hline 59 & 20 & 3 & 20 & 46 & 19 & 1 & 22 & 1 \\
\hline 57 & 25 & 2 & 21 & 54 & 41 & 2 & 23 & 1 \\
\hline
\end{tabular}

Australia provides evidence that recurrence score information influenced MDM treatment recommendations for both the node-negative and node-positive groups.

In patients with node-negative tumours, those initially receiving a CHT recommendation were more likely to change to HT than the reverse (change rates of $40 \% \mathrm{v} 17 \%$; $P=0.02)$, as reported by others. ${ }^{12-15}$ However, unlike in other studies, a high proportion (more than twothirds) of patients initially received a recommendation of HT alone and hence there was no overall change in chemotherapy use (12 patients changed from HT to CHT and 12 from CHT to HT). The high proportion of patients with node-negative tumours and with an initial recommendation of HT in this study appears to reflect an approach among this group of clinicians of basing treatments primarily on the degree of hormone sensitivity of the tumour, with the understanding that these patients would gain little extra benefit from chemotherapy. A number of these patients had unexpectedly high recurrence score results, which suggests that such an approach may sometimes lead to undertreatment.

In patients with node-positive tumours, those initially receiving a CHT recommendation were also more likely to change to HT than the reverse (change rates of $32 \% \mathrm{v} 8 \%$ ), although the difference in rates was not significant $(P=0.14)$. In contrast to the node-negative group, almost three-quarters of the patients with node-positive tumours received an initial recommendation for $\mathrm{CHT}$, and there was a statistically significant reduction in recommendations for CHT post-assay (from $74 \%$ to $52 \%$, $P=0.003)$. The reduction in CHT recommendations in the node-positive group is consistent with results seen in other studies of the impact of Oncotype DX assay on adjuvant decision making in patients with nodepositive tumours. ${ }^{13,16}$ This suggests that in terms of reducing possible overtreatment, the Oncotype DX assay might have its greatest impact in this group.

While confirmation of the impact of the recurrence score on chemotherapy benefit in RCTs is pending (eg, TAILORx [NCT00310180], RxPONDER [NCT01272037]), our data suggest that use of the assay can spare patients potentially unnecessary treatment as well as identify patients for whom potentially lifesaving therapy might otherwise be omitted. In both patients with nodenegative and those with node-positive tumours, changes in recommendations were made in directions consistent with the recurrence score categories, suggesting that assay results had a strong impact on final decisions. As the recurrence score has been validated to predict both distant recurrence risks and responsiveness to chemotherapy in both the node-negative and node-positive 
4 Patients with treatment recommendations changed from hormone therapy to chemotherapy plus hormone therapy

\begin{tabular}{lccc}
$\begin{array}{l}\text { Patient } \\
\text { age }\end{array}$ & $\begin{array}{c}\text { Tumour } \\
\text { size } \\
(\mathrm{mm})\end{array}$ & $\begin{array}{c}\text { Tumour } \\
\text { grade }\end{array}$ & $\begin{array}{c}\text { Recurrence } \\
\text { score }\end{array}$ \\
\hline
\end{tabular}

\begin{tabular}{lccl}
\multicolumn{2}{l}{ Node-negative } & \\
37 & 18 & 2 & 22 \\
27 & 25 & 2 & 25 \\
72 & 12 & 3 & 26 \\
63 & 5 & 1 & 29 \\
58 & 15 & 1 & 29 \\
65 & 8 & 3 & 29 \\
66 & 20 & 3 & 33 \\
60 & 15 & 2 & 34 \\
66 & 12 & 3 & 34 \\
66 & 9 & 3 & 34 \\
38 & 30 & 2 & 35 \\
61 & 13 & 3 & 48
\end{tabular}

Node-positive (1 node)

68

20

2

37

groups, these shifts in treatment recommendations arguably allow physicians to direct individual patients toward therapies that ultimately may be associated with better health outcomes. The result is more precise individualisation of therapy from both the MDM and the treating physician.

In both the node-negative and node-positive groups, about $10 \%$ of patients elected not to follow the post-assay treatment recommendation. Patient treatment decisions went against the MDM recommendations, both toward CHT and toward HT. Reasons for not following treatment recommendations might include patient preference, patient anxiety about one treatment regimen or the other, and varying levels of patient trust in the Oncotype DX recurrence score assay.

The lack of routine assessment of $\mathrm{Ki}-67$ levels may be seen as a limitation of this study. A report in 2011 suggested that an assessment of $\mathrm{Ki}-67$ levels, along with ER, PR and HER2 status, could provide similar prognostic information to the Oncotype DX assay. ${ }^{19}$ However, a subsequent international working group concluded that large variations in analytic methods have limited the routine reliance on immunohistochemical assessment of $\mathrm{Ki}-67$ in clinical practice. ${ }^{20}$

Another limitation of our study is that MDMs at only three academic breast cancer units in Melbourne participated. Therefore, our results (which reflect the collective opinions of participating physicians) may not reflect nationwide practices. Attendance at the MDMs may have varied, and other factors such as the passage of time could have affected the second MDM recommendation, although the time between assessments was generally about 3 weeks. There may have been other biases.

In conclusion, this study provides evidence that the Oncotype DX assay influences treatment recommendations for $\mathrm{HR}+$ early-stage invasive breast cancer in the Australian MDM setting. Most of the recommended changes were toward lower intensity treatment regimens. The health economic impact of this assay in Australia remains to be investigated, but the impact of this shift on quality of life should not be underestimated.

Competing interests: Genomic Health Inc provided the Oncotype DX assays used in this study at no cost, and provided research funds for conducting the study. Richard de Boer is a member of the Speakers Bureau for Genomic Health and has received an honorarium for one lecture.

Calvin Chao and Carl Yoshizawa are employees and shareholders of Genomic Health. Bruce Mann is a member of the Speakers Bureau for Genomic Health and has participated on an advisory board for Genomic Health.

Received 1 Sep 2012, accepted 4 Mar 2013.

1 Australian Institute of Health and Welfare Cancer in Australia 2010: an overview. Canberra: AlHW, 2010. (AlHW Cat. No. CAN 56; Cancer Series No. 60.) http://www.aihw.gov.au/ publication-detail/?id=6442472459 (accessed Feb 2013).

2 Ernst MF, Voogd AC, Coebergh JW, Roukema JA. Breast carcinoma diagnosis, treatment, and prognosis before and after the introduction of mass mammographic screening. Cancer 2004 100: 1337-1344.

3 Lester S, Cotran RS. The breast. In: Cotran RS, Kumar V, Collins T, editors. Robbins pathologic basis of disease. 6th ed. Philadelphia, Pa: WB Saunders Company, 1999: 1093-1119.

4 Early Breast Cancer Trialists' Cooperative Group. Polychemotherapy for early breast cancer: an overview of the randomised trials. Lancet 1998; 352: 930-942.

5 Goldhirsch A, Ingle JN, Gelber RD, et al. Thresholds for therapies: highlights of the St Gallen International Expert Consensus on the primary therapy of early breast cancer 2009. Ann Oncol 2009; 20: 1319-1329.
6 McEvoy SP, Ingram DM, Byrne MJ, et al. Breast cancer in Western Australia: clinical practice and clinical guidelines. Med J Aust 2004; 181: 305-309.

7 White V, Pruden M, Giles G, et al. The management of early breast carcinoma before and after the introduction of clinical practice guidelines. Cancer 2004; 101: 476-485.

8 Paik S, Shak S, Tang G, et al. A multigene assay to predict recurrence of tamoxifen-treated, nodenegative breast cancer. N Engl J Med 2004; 351: 2817-2826.

9 Albain KS, Barlow WE, Shak S, et al. Prognostic and predictive value of the 21-gene recurrence score assay in postmenopausal women with node-positive, oestrogen-receptor-positive breast cancer on chemotherapy: a retrospective analysis of a randomised trial. Lancet Oncol 2010; 11: 55-65.

10 Dowsett M, Cuzick J, Wale C, et al. Prediction of risk of distant recurrence using the 2l-gene recurrence score in node-negative and nodepositive postmenopausal patients with breast cancer treated with anastrozole or tamoxifen: TransATAC study. J Clin Oncol 2010; 28: 18291834.

11 Paik S, Tang G, Shak S, et al. Gene expression and benefit of chemotherapy in women with nodenegative, estrogen receptor-positive breast cancer. J Clin Oncol 2006; 24: 3726-3734.

12 Albanell J, González A, Ruiz-Borrego M, et al. Prospective transGEICAM study of the impact of the 21-gene Recurrence Score assay and traditional clinicopathological factors on adjuvant clinical decision making in women with estrogen receptor-positive $(\mathrm{ER}+)$ node-negative breast cancer. Ann Oncol 2012; 23: 625-631.

13 Blohmer JU, Rezai M, Kümmel S, et al. Using the 21-gene assay to guide adjuvant chemotherapy decision-making in early-stage breast cancer: a cost-effectiveness evaluation in the German setting. J Med Econ 2013; 16: 30-40.

14 Klang SH, Hammerman A, Liebermann N, et al. Economic implications of 21-gene breast cancer risk assay from the perspective of an Israelimanaged health-care organization. Value Health 2010; 13: 381-387.

15 Lo SS, Mumby PB, Norton J, et al. Prospective multicenter study of the impact of the 21-gene recurrence score assay on medical oncologist and patient adjuvant breast cancer treatment selection. JClin Oncol 2010; 28: 1671-1676.

16 Oratz R, Kim B, Chao C, et al. Physician survey of the effect of the 21-gene recurrence score assay results on treatment recommendations for patients with lymph node-positive, estrogen receptor-positive breast cancer. J Oncol Pract 2011; 2: 94-99.

17 Kamal AH, Loprinzi CL, Reynolds C, et al. Breast medical oncologists' use of standard prognostic factors to predict a 21-gene recurrence score. Oncologist 2011; 16:1359-1366.

18 National Breast Cancer Centre. Multidisciplinary meetings for cancer care: a guide for health service providers. Camperdown, NSW: NBOCC, 2005.

19 Cuzick J, Dowsett M. Pineda S, et al. Prognostic value of a combined estrogen receptor, progesterone receptor, $\mathrm{Ki}-67$, and human epidermal growth factor receptor 2 immunohistochemical score and comparison with the Genomic Health recurrence score in early breast cancer. J Clin Oncol 2011; 29: 4273-4278.

20 Dowsett M, Nielsen TO, A'Hern R, et al. Assessment of Ki67 in breast cancer: recommendations from the International Ki67 in Breast Cancer Working Group. J Natl Cancer Inst 2011; 103: 1656-1664. 